\title{
Magma mixing recorded by chronologically constrained melt inclusions
}

\author{
ROSARIO ESPOSITO ${ }^{1}$, KIMBERLY BADESCU $^{1}$, JEREMY \\ BOYCE $^{2}$, CRAIG E. MANNING ${ }^{1}$, ROBERT J. BODNAR ${ }^{3}$, \\ MatTHew Steele-McInNIS ${ }^{4}$, BenedeTto De VIVO
}

${ }^{1}$ Earth, Planetary and Space Sciences, UCLA, Los Angeles, CA 90095-1567, USA. rosesposito@g.ucla.edu

${ }^{2}$ Astromaterials Research and Exploration Science (ARES) Division NASA Johnson Space Center Mail Code XI3, Building 31.drjwboyce@gmail.com

${ }^{3}$ Department of Geosciences (0420), 4044 Derring Hall, 926 West Campus Drive, Virginia Tech.rjb@vt.edu

${ }^{4}$ Earth and Atmospheric Sciences, University of Alberta, Edmonton, AB, T6G 2E3 Canada. steelema@ualberta.ca ${ }^{5}$ Università Pegaso, Piazza Trieste e Trento 48, 80132 Napoli, Italy.benedetto.devivo@unipegaso.it

Understanding the reliability of melt inclusions (MI) has become more important as the use of this technique has increased in recent decades. Generally, the chemical compositions of MI in a single sample or even in the same crystal host span a wide range. Here, we studied a single olivine phenocryst from the Solchiaro eruption on Procida Island (Southern Italy) to understand the reliability of MI to record magma mixing processes. The selected olivine hosts multiple MI and chromite inclusions and shows reverse zoning from $\mathrm{FO}_{\sim 83}$ to $\mathrm{FO}_{\sim 87}$. We recognized three groups of $\mathrm{MI}$ based on petrography and $\mathrm{P}$ X-ray mapping that we refer to as early MI (EMI), intermediate MI (IMI), and late MI (LMI). We analyzed the MI for their major element compositions plus $\mathrm{S}$ and $\mathrm{Cl}$. These three groups of $\mathrm{MI}$ are discriminated by their major element compositions. EMI represent the first stage of olivine formation, whereas IMI formed as a result of fractional crystallization and progressive growth. LMI formed as the magma was mixing and represent the last stage of crystallization of the olivine before eruption. The LMI represent a melt inclusion assemblage (MIA) sensu strictu. LMI were all trapped at the same time and at the same chemical and physical conditions because they were trapped along a single olivine growth band as revelaed by $\mathrm{P}$ X-ray maps. These MI contain only glass at room temperature. The LMI show correlations between some major element compositions of LMI increase or decrease with inclusion size up to $\sim 20 \mu \mathrm{m}$ and plateaud as MI are $\geq 22 \mu \mathrm{m}$. This correlation suggests that larger LMI $(\geq 22 \mu \mathrm{m})$ are reliable carriers of the pre-eruptive melt composition. This study shows that MI accurately record mixing processes during the differentiation of the magma before eruption. 